\title{
Kidney Diseases
}

\section{Editors-in-Chief}

Zhi-Hong Liu - Nanjing University, Nanjing, China

\section{Consulting Editor}

Giuseppe Remuzzi - Mario Negri Institute for Pharmacological Research, Bergamo, Italy

\section{Associate Editors}

Chunsun Dai - Nanjing Medical University, Nanjing, China

Zheng Dong - Augusta University, Augusta, GA, USA

Chuan-Ming Hao - Fudan University, Shanghai, China

John Cijiang He - Icahn School of Medicine at Mount Sinai, New York, NY, USA

Gui-Sen Li - Sichuan Provincial People's Hospital, Sichuan, China

Jing Nie - Southern Medical University, Guangzhou, China

Jan Novak - University of Alabama at Birmingham, Birmingham, AL, USA

Fan Yi - Shandong University, Jinan, China

Shengqiang Yu - Second Military Medical University, Shanghai, China

Ai-Hua Zhang - Nanjing Medical University, Nanjing, China

Hong Zhang - Peking University, Beijing, China

Jinghong Zhao - Third Military Medical University, Chongqing, China

\section{Editorial Board}

Ariela Benigni - Mario Negri Institute for Pharmacological Research, Bergamo, Italy Giovambattista Capasso - University of Campania "Luigi Vanvitelli", Naples, Italy Tak Mao Daniel Chan - The University of Hong Kong, Hong Kong, SAR, China Jianghua Chen - Zhejiang University, Hangzhou, China Nan Chen - Shanghai Jiao Tong University, Shanghai, China Alfred K. Cheung - University of Utah, Salt Lake City, UT, USA

Ricardo Correa-Rotter - National Medical Science and Nutrition Institute Salvador Zubiran,

Mexico City, Mexico

Kai-Uwe Eckardt - Charité - University Medicine Berlin, Berlin, Germany

Maik Gollasch - Charité - University Medicine Berlin, Berlin, Germany

Lynn Gomez - University of the Philippines, Bacoor, Philippines

Rujun Gong - University of Toledo College of Medicine, Toledo, OH, USA

Youfei Guan - Dalian Medical University, Dalian, China

Hai An Ha Phan - Hanoi Medical University, Hanoi, Vietnam

Berthold Hocher - University of Potsdam, Nuthetal, Germany

Fan-Fan Hou - Southern Medical University, Guangzhou, China

Vivekanand Jha - George Institute for Global Health, New Delhi, India

Duk-Hee Kang - Ewha Womans University, Seoul, Republic of Korea

Shin-Wook Kang - Yonsei University, Seoul, Republic of Korea 
Jeffrey B. Kopp - National Institute of Diabetes and Digestive and Kidney Diseases, Bethesda, MD, USA

Matthias Kretzler - University of Michigan, Ann Arbor, MI, USA

Hui Yao Lan - The Chinese University of Hong Kong, Hong Kong, SAR, China Philip K.T. Li - The Chinese University of Hong Kong, Hong Kong, SAR, China Sun Lin - Central South University, Changsha, China Bi-Cheng Liu - Southeast University, Nanjing, China Youhua Liu - University of Pittsburgh, Pittsburgh, PA, USA Toshio Miyata - Tohoku University, Sendai, Japan Masaomi Nangaku - The University of Tokyo, Tokyo, Japan Vlado Perkovic - George University, Newtown, NSW, Australia Qi Qian - Mayo Clinic College of Medicine, Rochester, MN, USA Michael Rocco - Wake Forest University, Winston-Salem, NC, USA Claudio Ronco - St. Bartolo Hospital, Vicenza, Italy Pierre Ronco - UPMC University Pierre and Marie Curie Paris 6, Paris, France Xiong Z. Ruan - University College London, London, UK Ivan Rychlik - Charles University, Prague, Czech Republic Bancha Satirapoj - Phramongkutklao Hospital, Bangkok, Thailand Stuart J. Shankland - University of Washington, Seattle, WA, USA Shaolin Shi - Nanjing University, Nanjing, China Yusuke Suzuki - Juntendo University, Tokyo, Japan Charles Swanepoel - University of Cape Town, Cape Town, South Africa Cheuk Chun Szeto - The Chinese University of Hong Kong, Hong Kong, SAR, China Sydney Tang - The University of Hong Kong, Hong Kong, SAR, China Vladimir Tesar - Charles University, Prague, Czech Republic Yasuhiko Tomino - Medical Corporation Showakai, Tokyo, Japan Marcello Tonelli - University of Calgary, Calgary, AB, Canada

Hernán Trimarchi - British Hospital Buenos Aires, Buenos Aires, Argentina Raymond Vanholder - Ghent University Hospital - UZ Ghent, Ghent, Belgium Christoph Wanner - University Hospital of Würzburg, Würzburg, Germany Qihe Xu - King's College London, London, UK Chih-Wei Yang - Chang Gung Memorial Hospital, Taipei, Taiwan, ROC Tianxin Yang - University of Utah, Salt Lake City, UT, USA Lianghong Yin - Jinan University, Guangzhou, China Xueqing Yu - Sun Yat-Sen University, Guangzhou, China Caihong Zeng - Jinling Hospital, Nanjing, China Ming-hui Zhao - Peking University, Beijing, China Xiaoai Zhao - Stanford University, Stanford, CA, USA Haitao Zhang - Nanjing University, Nanjing, China Shougang Zhuang - Rhode Island Hospital, Providence, RI, USA 
S. Karger

Medical and Scientific Publishers

Basel $\cdot$ Freiburg $\cdot$ Hartford $•$ Oxford $•$ Bangkok $\cdot$ Dubai $\cdot$ Kuala Lumpur $•$ Melbourne $\cdot$ Mexico City $\cdot$ Moscow $•$ New Delhi $\bullet$ Paris $\bullet$ Shanghai $\cdot$ Tokyo

\section{Disclaimer}

The statements, opinions and data contained in this publication are solely those of the individual authors and contributors and not of the publisher and the editor(s). The appearance of advertisements in the journal is not a warranty, endorsement, or approval of the products or services advertised or of their effectiveness, quality or safety. The publisher and the editor(s) disclaim responsibility for any injury to persons or property resulting from any ideas, methods, instructions or products referred to in the content or advertisements.

Drug Dosage

The authors and the publisher have exerted every effort to en sure that drug selection and dosage set forth in this text are in accord with current recommendations and practice at the time of publication. However, in view of ongoing research, changes in government regulations, and the constant flow of information relating to drug therapy and drug reactions, the reader is urged to check the package insert for each drug for any change in indications and dosage and for added warnings and precautions. This is particularly important when the recommended agent is a new and/or infrequently employed drug.
All rights reserved.

No part of this publication may be translated into other languages, reproduced or utilized in any form or by any means, electronic or mechanical, including photocopying, recording, microcopying, or by any information storage and retrieval system, without permission in writing from the publisher or in the case of photocopying, direct payment of a specified fee to the Copyright Clearance Center (see "General Information")

(c) Copyright $2019 / 2020$ by S. Karger AG,

CH-4009 Basel (Switzerland)

Printed on acid-free and non-aging paper (ISO 9706) 


\section{No. 1}

Review Articles

1 Artificial Intelligence in Nephrology: How Can Artificial Intelligence Augment Nephrologists' Intelligence? Xie, G.; Chen, T.; Li, Y. (Beijing); Chen, T. (Nanjing); Li, X. (Beijing); Liu, Z. (Nanjing)

7 Functional MRI as a Tool for Evaluating Interstitial Fibrosis and Prognosis in Kidney Disease

Zhang, J.; Zhang, L.J. (Nanjing)

13 Obesity and the Survival of Critically III Patients with Acute Kidney Injury: A Paradox within the Paradox? Schiffl, H. (Munich)

22 The Role of Endothelin and Endothelin Antagonists in Chronic Kidney Disease

Raina, R. (Akron, OH); Chauvin, A. (Rootstown, OH); Chakraborty, R. (Akron, OH); Nair, N. (Cleveland, OH); Shah, H. (Rootstown, OH); Krishnappa, V. (Akron, OH/Rootstown, OH); Kusumi, K. (Akron, OH)

Research Articles

35 Dyslipidemia and Intraperitoneal Inflammation Axis in Peritoneal Dialysis Patients: A Cross-Sectional Pilot Study Stepanova, N.; Driianska, V.; Savchenko, S. (Kyiv)

43 A Novel COL4A5 Splicing Mutation Causes Skipping of Exon 14 in a Chinese Family with Alport Syndrome Gao, E.; Yang, X. (Nanjing); Si, N.; Liu, K. (Beijing); Wang, J.-Q.; Liu, Z. (Nanjing)

50 Intravascular Volume Modulates the Outcome Predictive Capacity of Clinical Renal Function Biomarkers in Clinically "Euvolemic" Chronic Heart Failure Patients Miller, W.L.; Grill, D.E.; Qian, Q. (Rochester, MN)

59 Progression of Metabolic Acidosis in Chronic Kidney Disease Tanemoto, M. (Kuki/Atami)

No. 2

Review Articles

65 Treatment of Renal Anemia with Roxadustat: Advantages and Achievement

Li, Z.-L.; Tu, Y.; Liu, B.-C. (Nanjing)

74 Patient-Centred Outcomes in Anaemia and Renal Disease: A Systematic Review

Staibano, P.; Perelman, I.; Lombardi, J.; Davis, A.; Tinmouth, A.; Carrier, M.; Stevenson, C.; Saidenberg, E. (Ottawa, ON)

85 Detailed Review of Chronic Kidney Disease

Kakitapalli, Y.; Ampolu, J. (Tekkali); Madasu, S.D. (Bapatla);

Sai Kumar, M.L.S. (Jamshedpur)
92 Pseudoxanthoma Elasticum: An Interesting Model to Evaluate Chronic Kidney Disease-Like Vascular Damage without Renal Disease

D’Marco, L. (Valencia); Lima-Martínez, M. (Bolívar); Karohl, C.

(Porto Alegre); Chacín, M.; Bermúdez, V. (Barranquilla)

Research Articles

98 The Presence of Renal IgG Deposits in Necrotizing Crescentic Glomerulonephritis Associated with ANCA Is Not Related to Worse Renal Clinical Outcomes

Dudreuilh, C. (Tours); Fakhouri, F. (Nantes); Vigneau, C. (Rennes); Augusto, J.-F. (Angers); Machet, M.-C.; Rabot, N. (Tours); Chapal, M.; Charpy, V. (Nantes); Barbet, C.; Büchler, M.; Halimi, J.-M.; Gatault, P. (Tours)

109 Hypomagnesemia and Short-Term Mortality in Elderly Maintenance Hemodialysis Patients

Lu, C.; Wang, Y.; Wang, D.; Nie, L.; Zhang, Y.; Lei, Q.; Xiong, J.; Zhao, J. (Chongqing)

119 Morphological Features of Minimal Change Disease and Focal Segmental Glomerulosclerosis Using Repeat Biopsy and Parietal Epithelial Cell Marker Suzuki, T. (Kanagawa/Chiba); Kohatsu, K.; Han, W.; Watanabe, S. (Kanagawa); Yahagi, K. (Yokohama); Nakata, M.; Ueno, T.; Ichikawa, D.; Imai, N. (Kanagawa); Shirai, S. (Yokohama); Koike, J. (Kawasaki); Shibagaki, Y. (Kanagawa)

125 Plasma Metabolomics Profiling in Maintenance Hemodialysis Patients Based on Liquid Chromatography Quadrupole Timeof-Flight Mass Spectrometry

Chen, Y. (Shanghai/Nanjing); Wen, P.; Yang, J. (Nanjing); Niu, J. (Shanghai)

No. 3

135 Publisher's Note

World Kidney Day 2020: Editorial

136 Kidney Health for Everyone Everywhere - From Prevention to Detection and Equitable Access to Care

Li, P.K.-T. (Hong Kong); Garcia-Garcia, G. (Guadalajara); Lui, S.-F. (Hong Kong); Andreoli, S. (Indianapolis, IN); Fung, W.W.-S. (Hong Kong); Hradsky, A. (Brussels); Kumaraswami, L. (Chennai); Liakopoulos, V. (Thessaloniki); Rakhimova, Z. (Brussels); Saadi, G. (Giza); Strani, L. (Brussels); Ulasi, I. (Ituku-Ozalla); Kalantar-Zadeh, K. (Orange, CA); for the World Kidney Day Steering Committee

$\begin{array}{ll}\begin{array}{l}\text { karger@karger.com } \\ \text { www.karger.com }\end{array} & \text { (c) 2020 S. Karger AG, Basel } \\ \text { Karger } & \begin{array}{l}\text { Access to full text and tables of contents, } \\ \text { including tentative ones for forthcoming issues: } \\ \text { www.karger.com/kdd_issues }\end{array}\end{array}$


Guidelines

144 Executive Summary: Clinical Practice Guideline for Autosomal Dominant Polycystic Kidney Disease in China

Mei, C.-L.; Xue, C.; Yu, S.-Q.; Dai, B. (Shanghai); Chen, J.-H. (Hangzhou) Li, Y. (Shijiazhuang); Chen, L.-M. (Beijing); Liu, Z.-S. (Zhengzhou); Wu, Y.-G. (Hefei); Hu, Z. (Jinan); Zha, Y. (Gui Yang); Liu, H. (Changsha); Zhuang, Y.-Z. (Fuzhou); Zhang, C. (Wuhan); Xiao, X.-C. (Changsha); Wang, Y. (Peking); Li, G.-S. (Chengdu); Ma, Y.-Y.; Li, L. (Shanghai); ADPKD Clinical Guideline Working Group

Review Articles

150 Lymphatic Vessels Enhancing Adaptive Immunity Deteriorates Renal Inflammation and Renal Fibrosis Wu, J.; Pei, G.; Zeng, R.; Xu, G. (Wuhan)

157 Pharmacotherapeutic Management of Neuropathic Pain in End-Stage Renal Disease

Raouf, M. (Federal Way, WA); Bettinger, J. (Saratoga, NY); Wegrzyn, E.W. (Albany, NY); Mathew, R.O. (Columbia, SC); Fudin, J.J. (Albany, NY)

Research Articles

168 Leukemia Inhibitory Factor Signaling Enhances Production of Galactose-Deficient IgA1 in IgA Nephropathy

Yamada, K. (Birmingham, AL/Tokyo); Huang, Z. (Birmingham, AL); Raska, M. (Birmingham, AL/Olomouc); Reily, C.; Anderson, J.C. (Birmingham, AL); Suzuki, H. (Birmingham, AL/Tokyo); Kiryluk, K.; Gharavi, A.G. (New York, NY); Julian, B.A.; Willey, C.D.; Novak, J. (Birmingham, AL)

181 FGF/FGFR2 Protects against Tubular Cell Death and Acute Kidney Injury Involving Erk1/2 Signaling Activation Xu, Z.; Zhu, X.; Wang, M.; Lu, Y.; Dai, C. (Nanjing)

195 Sex Differences in Kidney Stone Disease in Chinese Patients with Type 2 Diabetes Mellitus

Xiao, Y.; Wei, L.; Xiong, X.; Yang, Y.; Li, L.; Yang, M.; Deng, F.; Sun, L. (Changsha)

204 Comparison between the Beta-2 Microglobulin-Based Equation and the CKD-EPI Equation for Estimating GFR in CKD Patients in China: ES-CKD Study Yue, L.; Pan, B.; Shi, X.; Du, X. (Nanjing)

No. 4

Review Articles

215 Diabetic Kidney Disease: Challenges, Advances, and Opportunities

Chen, Y. (New York, NY/Shanghai); Lee, K. (New York, NY); Ni, Z.

(Shanghai); He, J.C. (New York, NY)

226 Application of Histone Deacetylase Inhibitors in Renal Interstitial Fibrosis

Nie, L.; Liu, Y.; Zhang, B.; Zhao, J. (Chongqing)

236 Histone Deacetylases Take Center Stage on Regulation of Podocyte Function

Liu, M.; Qiao, Z.; Zhang, Y.; Zhan, P.; Yi, F. (Jinan)

247 Twist 1: A Double-Edged Sword in Kidney Diseases

Ren, J.; Crowley, S.D. (Durham, NC)

Research Articles

258 Localization of Cell Receptor-Related Genes of SARS-CoV-2 in the Kidney through Single-Cell Transcriptome Analysis Chen, Q.-L. (Nanjing); Li, J.-Q. (Hangzhou); Xiang, Z.-D.; Lang, Y.

(Nanjing); Guo, G.-J. (Hangzhou); Liu, Z.-H. (Nanjing)
271 Aggressive Quarantine Measures Reduce the High Morbidity of COVID-19 in Patients on Maintenance Hemodialysis and Medical Staff of Hemodialysis Facilities in Wuhan, China Li, J.; Yang, Y.; Gong, M.; Shi, J.; Zhou, X.; Xing, X.; Pan, H.; Guo, S.; Chang, X.; Cheng, A.; Wang, Y.; Ge, S.; Xiao, F.; Yao, Y.; Ning, Y.; He, F.; $\mathrm{Xu}, \mathrm{G}$. (Wuhan)

284 The Value of Renal Biopsy in Non-Insulin-Dependent Diabetes Mellitus in Singapore over the Past Two Decades

Woo, K.T.; Chan, C.M.; Lim, C.; Choo, J.; Chin, Y.M.; Teng, E.W.L.; Mok, I, Kwek, J.L.; Tan, C.S.; Tan, H.Z.; Loh, A.H.L.; Choong, H.L.; Tan, H.K.; Lee, G.S.L.; Lee, E.; Wong, K.S.; Tan, P.H.; Foo, M. (Singapore)

299 Effects of Erythropoietin-Stimulating Agents on Blood Pressure in Patients with Non-Dialysis CKD and Renal Anemia Ohki, K.; Wakui, H.; Uneda, K.; Azushima, K.; Haruhara, K.; Kinguchi, S.; Urate, S.; Yamada, T.; Yamaji, T.; Kobayashi, R.; Kanaoka, T.; Minegishi, S.; Ishigami, T.; Fujikawa, T.; Toya, Y.; Tamura, K. (Yokohama)

No. 5

Letter to the Editor

309 Nomenclature for Kidney Function and Disease: Executive Summary and Glossary from a Kidney Disease: Improving Global Outcomes (KDIGO) Consensus Conference Levey, A.S. (Boston, MA); Eckardt, K.-U. (Berlin); Dorman, N.M. (Philadelphia, PA); Christiansen, S.L. (Chicago, IL); Cheung, M.; Jadoul, M. (Brussels); Winkelmayer, W.C. (Houston, TX)

Review Articles

318 Acute Kidney Injury in the $\mathbf{2 0 1 9}$ Novel Coronavirus Disease Qian, J.-Y.; Wang, B.; Liu, B.-C. (Nanjing)

324 Mechanisms of Podocyte Detachment, Podocyturia, and Risk of Progression of Glomerulopathies Trimarchi, H. (Buenos Aires)

330 Advances in Pathogenesis of Idiopathic Membranous Nephropathy

Xu, Z.; Chen, L.; Xiang, H.; Zhang, C.; Xiong, J. (Wuhan)

Research Articles

346 A Rat Model with Multivalve Calcification Induced by Subtotal Nephrectomy and High-Phosphorus Diet

Wang, L.; Tang, R.; Zhang, Y. (Nanjing); Liu, Z. (Shanghai); Chen, S.; Song, K.; Guo, Y.; Zhang, L.; Wang, X.; Wang, X.; Liu, H.; Zhang, X.; Liu, B.-C. (Nanjing)

355 Raised Plasma Levels of Asymmetric Dimethylarginine Are Associated with Pathological Type and Predict the Therapeutic Effect in Lupus Nephritis Patients Treated with Cyclophosphamide

Zhang, L.; Zhang, K.; Dong, W.; Li, R.; Huang, R.; Zhang, H.; Shi, W.; Liu, S.; Li, Z.; Chen, Y.; Ye, Z.; Liang, X.; Yu, X. (Guangzhou)

364 The Relationship between Dialysis Metrics and Patient-Reported Cognition, Fatigue, and Physical Function Sturgill, D.A.; Bal, N.; Nagavally, S.; Wolfgram, D.F. (Milwaukee, WI)

371 Red Blood Cell Distribution Width and Neutrophil-to-Lymphocyte Ratio in Predicting Adverse Outcomes of Acute Kidney Injury in Hospitalized Patients Zhu, J. (Changsha/Augusta, GA); Zeng, C.; Zhang, L.; Shu, S.; Liu, Y.; Chen, G.; Liu, H.; Liu, Y. (Changsha); Dong, Z. (Augusta, GA)

382 Erratum

384 Erratum 


\section{No. 6}

Review Articles

385 Leveraging Data Science for a Personalized Haemodialysis Hueso, M. (L'Hospitalet de Llobregat); de Haro, L. (Barcelona); Calabia, J. (Girona); Dal-Ré, R. (Madrid); Tebé, C. (L'Hospitalet de Llobregat);

Gibert, K. (Barcelona); Cruzado, J.M. (L'Hospitalet de Llobregat); Vellido, A. (Barcelona)

395 The Protective Role of Klotho in CKD-Associated Cardiovascular Disease

Bi, X.; Yang, K.; Zhang, B.; Zhao, J. (Chongqing)

Systematic Review and Meta-Analysis

407 Effect of Statins on Renal Function and Total Kidney Volume in Autosomal Dominant Polycystic Kidney Disease

Xue, C.; Zhang, L.-M.; Zhou, C.; Mei, C.-L.; Yu, S.-Q. (Shanghai)

Review Article

414 Acute Kidney Injury Relevant to Tubulointerstitial Nephritis with Late-Onset Uveitis Superimposed by Thrombotic Microangiopathy: A Case Report and Review of the Literature Zhao, Y.; Huang, J.; Su, T.; Yang, Z.; Zheng, X.; Yang, L.; Zhou, X.; Yu, X.; Wang, H.; Wang, S.; Liu, G.; Yang, L. (Beijing)
Research Articles

422 Podocyte-Released Migrasomes in Urine Serve as an Indicator for Early Podocyte Injury

Liu, Y.; Li, S.; Rong, W.; Zeng, C.; Zhu, X.; Chen, Q.; Li, L.; Liu, Z.-H.; Zen, K. (Nanjing)

434 Duration of Serum Phosphorus Control Associated with Overall Mortality in Patients Undergoing Peritoneal Dialysis Gong, N.; Xiao, Z.; Zhang, F.; Zhong, X.; He, Y.; Yi, Z.; Tang, D.; Yang, C.; Lin, Y.; Nie, J.; Ai, J. (Guangzhou)

444 Spectrums and Prognosis of Kidney Disease in Patients with Ankylosing Spondylitis

He, D.; Wang, R. (Najing/Yangzhou); Liang, S.; Liang, D.; Xu, F.; Zeng, C.; Tang, Z. (Najing)

453 Effect of Low-Frequency Therapeutic Ultrasound on Induction of Nitric Oxide in CKD: Potential to Prevent Acute Kidney Injury

Dae, M.W.; Liu, K.D. (San Francisco, CA); Solomon, R.J. (Burlington, VT); Gao, D.W.; Stillson, C.A. (San Francisco, CA)

461 Erratum

462 Acknowledgement to the Reviewers 